\title{
Instillation-TIME (iTIME) as a rationale amendment for TIME conception. Is there enough evidence for the efficiency of negative pressure wound therapy with instillation (iNPWT) to announce a breakthrough idea for wound treatment?
}

\author{
A. Bobkiewicz, A. Studniarek, L. Krokowicz, M. Drews, T. Banasiewicz
}

\section{EDITORIAL}

\begin{abstract}
An increased number of patients developing difficult-to-heal wounds results in billions spending for chronic wound care management. Introduction of TIME conception has been a breakthrough idea for wound healing based on phase-adapted wound therapy that interacts and influence each other and included: $T$ - tissue management, $I$ - infection control, $\mathrm{M}$ - moisture balance, $\mathrm{E}-$ edge of the wound. Negative pressure wound therapy (NPWT) revolutionized the management of wound healing. Moreover, recently NPWT with installation (iNPWT) has gained the popularity of optimizing wound healing.

In the context of acceleration of wound healing, iNPWT meets the criteria of the TIME conception. All individual components of TIME strategy are found in iNPWT providing "all in one" conception. Such management is easy to apply, monitor and it is well-tolerated by patients. Based on the current studies, iNPWT is found to be an important alternative for other methods of wound healing. It is believed that iNPWT will evolve and gain popularity as an innovative treatment for TIME conception.
\end{abstract}

Keywords-TIME, negative pressure wound therapy, installation, wound healing

A LTHOUGH, the general principles of appropriate management of wound bed preparation had been known even earlier, it was in 2000 when Falanga et al. published the report of the phase-adapted wound healing using the acronym TIME $]^{1]}$ This conception is composed of four individual elements that interact and influence each other:

1) tissue management,

2) infection control,

3) moisture balance and

4) wound edge.

Manuscript received 25.05.2019; revised 04.07.2019. This work did not receive any financial support. Authors declare no conflict of interest.

Author affiliations: Department of General, Endocrinological Surgery and Gastroenterological Oncology Poznan University of Medical Sciences Przybyszewskiego 49, 60-355 Poznan, Poland, (AB, AS, LK, MD, TB)

*Correspondence to: Adam Bobkiewicz: bobofon007@gmail.com
The key TIME philosophy seems to promote significantly improved wound healing. Another breakthrough strategy that increased the rate of wound healing is NPWT. Since its introduction, NPWT has been considered a reasonably successful method for modern management of wound healing. ${ }^{2}$ In 1998, Fleischmann et al. combined the standard NPWT with a localized application of drugs. ${ }^{3}$ In 2003 , the first commercialized system of iNPWT was introduced to general practice. It combines the benefits of standard NPWT with incorporated, controlled and periodic installation of topical solution to the bed wound.

In the context of acceleration of wound healing, iNPWT meets the criteria of the TIME conception. It was proven that iNPWT facilitates the removal of wound exudate, cellular debris and inflammatory molecules that may impair the process of appropriate wound healing (representing Tissue management). The use of topical solutions facilitates the wound decontamination resulting in bacterial biofilm reduction (representing Infection control) ${ }^{4}[5]$ Composition of dressings with specially designed reticulated open-cell foam (ROCF) allows for appropriate adherence and distribution of instilled fluid within the wound. Moreover, application of instilled fluid keeps the moisture balance within the wound bed (representing Moisture balance) 6 [7 Negative pressure influences the re-epithelialization from the wound edges due to wound bed granulation, and remodeling of fibroblasts, extracellular matrix, as well as increased growth factor production 89 Using iNPWT, acceleration of wound filling and collagen deposition was observed within the wound bed, in both - experimental models as well as in clinical scenarios $10[11$

All above-mentioned mechanisms of action studied in in vitro and experimental studies were confirmed in clinical scenarios and in various types of wounds. Recently, a preliminary international consensus guideline was published to summarize the current state of the art regarding iNPWT! $!^{12}$ Moreover, further comprehensive reviews were published to 
define the use, settings and instilled solutions for optimal utility of iNPWT indicating the increased value of iNPWT in the field of wound healing 13 Currently, iNPWT is used as a method of choice in open fracture, pressure ulcer and nonhealing, complex postoperative wounds with a high rate of wound closure ${ }^{11} 16$ 17 17 In the recent multi-center prospective observational study, iNPWT was used for implant-associated infection following a knee or hip implant placement confirmed with the eradication of the wound infection in $75 \%$ of patients $\frac{18}{18}$ Similar results were achieved by others indicating the low rate of reinfection and high rate of wound closure using a skin graft, flaps or secondary closure 19.20

Based on our experience, iNPWT possesses the principles promoting wound healing and decisively fulfill the conception of TIME management. All individual components of TIME strategy are found in iNPWT providing "all in one" conception. Such management is easy to apply, monitor and it is well-tolerated by patients. Based on the current studies, iNPWT is found to be an important alternative for other methods of wound healing with an increased number of publications confirming its high efficiency. It is believed that iNPWT will evolve and gain popularity as an innovative treatment for TIME conception.

\section{REFERENCES}

[1] V. FALANGA, "Classifications for wound bed preparation and stimulation of chronic wounds," Wound repair and regeneration, vol. 8, no. 5, pp. 347-352, 2000.

[2] M. J. Morykwas, L. C. Argenta, E. I. Shelton-Brown, and W. McGuirt, "Vacuum-assisted closure: a new method for wound control and treatment: animal studies and basic foundation." Annals of plastic surgery, vol. 38, no. 6, pp. 553-562, 1997.

[3] W. Fleischmann, M. Russ, A. Westhauser, and M. Stampehl, "Vacuum sealing as carrier system for controlled local drug administration in wound infection," Der Unfallchirurg, vol. 101, no. 8, pp. 649-654, 1998.

[4] A. Gabriel, J. Shores, C. Heinrich, W. Baqai, S. Kalina, N. Sogioka, and S. Gupta, "Negative pressure wound therapy with instillation: a pilot study describing a new method for treating infected wounds," International wound journal, vol. 5, no. 3, pp. 399-413, 2008.

[5] P. L. Phillips, Q. Yang, and G. S. Schultz, "The effect of negative pressure wound therapy with periodic instillation using antimicrobial solutions on pseudomonas aeruginosa biofilm on porcine skin explants," International wound journal, vol. 10, no. s1, pp. 48-55, 2013.

[6] C. Lessing, P. Slack, K. Hong, D. Kilpadi, and A. McNulty, "Negative pressure wound therapy with controlled saline instillation (npwti): dressing properties and granulation response in vivo," Wounds, vol. 23, no. 10, p. 309, 2011.
[7] C. Mouës, F. Heule, and S. Hovius, "A review of topical negative pressure therapy in wound healing: sufficient evidence?" The American Journal of Surgery, vol. 201, no. 4, pp. 544-556, 2011.

[8] S. S. Scherer, G. Pietramaggiori, J. C. Mathews, M. J. Prsa, S. Huang, and D. P. Orgill, "The mechanism of action of the vacuum-assisted closure device," Plastic and reconstructive surgery, vol. 122, no. 3, pp. 786-797, 2008.

[9] A. Gabriel, J. Shores, C. Heinrich, W. Baqai, S. Kalina, N. Sogioka, and S. Gupta, "Negative pressure wound therapy with instillation: a pilot study describing a new method for treating infected wounds," International wound journal, vol. 5, no. 3, pp. 399-413, 2008.

[10] B. K. Leung, L. A. LaBarbera, C. A. Carroll, D. Allen, and A. K McNulty, "The effects of normal saline instillation in conjunction with negative pressure wound therapy on wound healing in a porcine model," Wounds, vol. 22, no. 7, pp. 179-87, 2010.

[11] D. Brinkert, M. Ali, M. Naud, N. Maire, C. Trial, and L. Teot, "Negative pressure wound therapy with saline instillation: 131 patient case series," International wound journal, vol. 10, no. s1, pp. 56-60, 2013.

[12] P. J. Kim, C. E. Attinger, J. S. Steinberg, K. K. Evans, B. Lehner, C. Willy, L. Lavery, T. Wolvos, D. Orgill, W. Ennis et al., "Negativepressure wound therapy with instillation: international consensus guidelines," Plastic and reconstructive surgery, vol. 132, no. 6, pp. 1569-1579, 2013.

[13] P. J. Kim, C. E. Attinger, O. Olawoye, B. D. Crist, A. Gabriel, R. D. Galiano, S. Gupta, J. Lantis Ii, L. Lavery, B. A. Lipsky et al., "Negative pressure wound therapy with instillation: review of evidence and recommendations," Wounds, vol. 27, no. 12, pp. S2-S19, 2015.

[14] A. Bobkiewicz, A. Studniarek, M. Drews, and T. Banasiewicz, "Negative pressure wound therapy with instillation (npwti): Current status, recommendations and perspectives in the context of modern wound therapy." Negative Pressure Wound Therapy Journal, vol. 3, no. 1, 2016.

[15] P. Kim, C. Attinger, J. Steinberg, and K. Evans, "Negative pressure wound therapy with instillation: past, present, and future." Surgical technology international, vol. 26, pp. 51-56, 2015.

[16] M. Tom Wolvos, "The use of negative pressure wound therapy with an automated, volumetric fluid administration: an advancement in wound care," Wounds, vol. 25, no. 3, pp. 75-83, 2013.

[17] W. Schreiner, O. Oster, P. Stapel, and H. Sirbu, "Vac instill@ therapynew option in septic thoracic surgery," Zentralblatt fur Chirurgie, vol. 138, no. 1, pp. 117-120, 2013.

[18] B. Lehner, S. Weiss, A. Suda, D. Witte et al., "Application of vac instill therapy in case of periprosthetic infection in hip arthroplasty," Infection, vol. 37, no. Suppl 1, pp. 13-17, 2009.

[19] G. Koster, "Management of early periprosthetic infections in the knee using the vacuum-instillation therapy," Infection, vol. 37, no. Suppl 1, pp. 18-20, 2009

[20] M. Schintler, E.-C. Prandl, G. Kreuzwirt, M. Grohmann, S. Spendel, E. Scharnagl et al., "The impact of vac instill in severe soft tissue infections and necrotizing fasciitis," Infection, vol. 37, no. Suppl 1, pp. 31-2, 2009. 